The University of Maine

DigitalCommons@UMaine

Wildlife, Fisheries, and Conservation Biology

Faculty Scholarship

Department of Wildlife, Fisheries, and Conservation Biology

$10-5-2021$

\title{
Modulation of ecosystem services by animal personalities
}

Malcolm L. Hunter Jr

Sara R. Boone

Allison M. Brehm

Alessio Mortelliti

Follow this and additional works at: https://digitalcommons.library.umaine.edu/wle_facpub

Part of the Animal Sciences Commons, and the Ecology and Evolutionary Biology Commons

This Article is brought to you for free and open access by DigitalCommons@UMaine. It has been accepted for inclusion in Wildlife, Fisheries, and Conservation Biology Faculty Scholarship by an authorized administrator of DigitalCommons@UMaine. For more information, please contact um.library.technical.services@maine.edu. 


\title{
Modulation of ecosystem services by animal personalities
}

\author{
Malcolm L Hunter Jr ${ }^{*}$, Sara R Boone, Allison M Brehm and Alessio Mortelliti
}

Conservationists rarely consider the roles individuals, with their own unique behavior, physiology, and genome, play in shaping ecosystem processes and consequently ecosystem services, but this is changing. An ongoing surge in research on animal personalities (that is, behavioral differences among individuals that are consistent over time and across contexts) is exposing the ecological roles of individuals to scientific scrutiny. Here, we present four broad examples of ecosystem services that are likely to be shaped by personalities: (1) pollination and seed dispersal, (2) regulation of pest species, (3) ecotourism, and (4) maintenance of soil quality. Although researchers have suggested diverse links between animal personality and ecosystem function, very few have examined this association. We outline a four-step process for quantifying and validating these linkages, leading to application for conservation practitioners, and conclude by recommending that accounting for behavioral variation should be incorporated into the management of ecosystem services.

Front Ecol Environ 2021; doi:10.1002/fee.2418

"When we try to pick out anything by itself, we find it hitched to everything else in the universe" - John Muir (1911)

The web of ecological connections has many long strands, 1 but conservationists rarely consider the roles of individual organisms - each with its own unique behavior, physiology, and genome - in shaping ecosystem processes and ecosystem services. We routinely evaluate the ecological function for populations of a particular species, especially for keystone or dominant species, but within populations there exist only black boxes. An ongoing spate of research on individual behavioral variation among animals - often termed personalities or behavioral types - is opening these black boxes to scrutiny.

Personality has been extensively studied in the fields of animal behavior and evolutionary ecology (Réale et al.2010; Wolf and Weissing 2012) but we are only beginning to learn about the ramifications for entire ecosystems (Brehm et al. 2019).

\section{In a nutshell:}

- Individual organisms have different personalities that shape their ecological roles and therefore their contributions to ecosystem services

- Understanding how personalities affect processes like pollination and seed dispersal or the regulation of pest species is a promising area for future research

- We propose a road map for ecologists to investigate the role of personalities in modulating ecosystem services and offer management advice based on their results

Department of Wildlife, Fisheries, and Conservation Biology, University of Maine, Orono, $M E^{*}$ (mhunter@maine.edu)
While the study of ecosystem services has grown substantially in recent years (Thom and Seidl 2016), ultimately the services provided by animals and plants are considered from the perspective of population averages (ie lumping services provided by each individual and ignoring variation among individuals). But what if individuals were to differ in the amount of service they provide, and what if these differences depended on their personality? To illustrate the role personalities may play in shaping ecosystem services we selected four examples that cover a wide range of services and taxa (Figure 1).

\section{Pollination and seed dispersal}

Isaac Watts famously penned "How doth the little busy bee/ Improve each shining hour/And gather honey all the day/ From every opening flower!" (Watts 1777). Despite Watt's careful observations, it is unlikely he understood the complexity of these important relationships between bees and flowers. Pollination and seed dispersal are two key ecological processes in which the mobility of animals allows them to provide a crucial service for plants. An estimated 78-94\% of global plant species rely on pollination by animals, particularly insects, bats, and birds (Ollerton et al. 2011). Bees, and especially honey bees (Apis mellifera), are quintessential pollinators that are often used to increase agricultural production. Multiple studies have demonstrated that bee personalities can influence colony survival, as well as facilitate effective pollination in varying habitats. Wray et al. (2011) examined differences in collective colony personality and found that more defensive colonies usually exhibited higher foraging activity and better fitness. Walton and Toth (2016) determined that the personality of individual bees can contribute to the division of labor in a hive, whereas Burns 

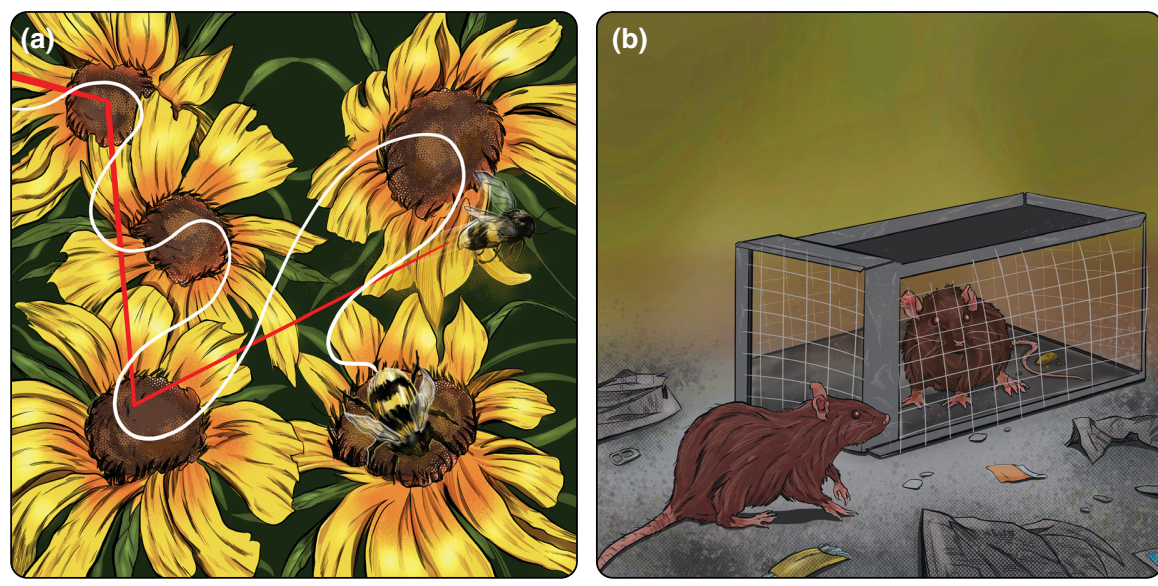

(c)

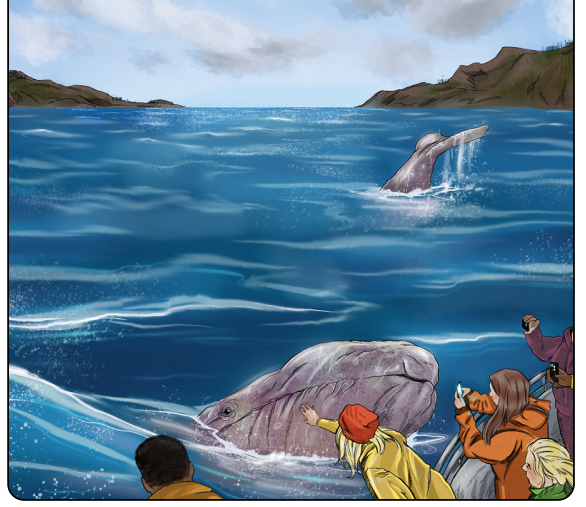

(d)

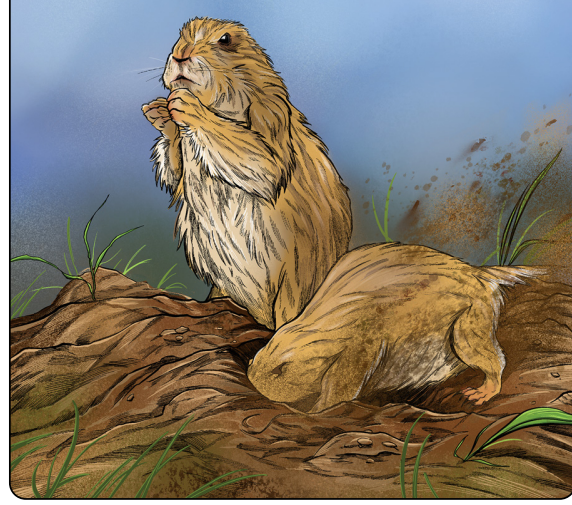

Figure 1. Personality traits may shape four important ecosystem services. (a) In pollination systems "fast and inaccurate" or "slow and precise" foragers may succeed in different foraging situations. (b) Personality traits impact the effect of control methods on pest species, for example, by influencing an individual's trappability. (c) Much ecotourism, such as the whalewatching industry, is dependent on "friendly", "curious", or "playful" individual cetaceans. (d) Prairie dogs (Cynomys spp) can transform grasslands with their extensive burrow systems, and individual differences in activity patterns likely mean that some individuals have a disproportionate influence on soil processes. All illustrations are original artwork provided by $\mathrm{K}$ Currier. dispersal distance, whether an animal returns for the seed, and so forth). For example, Brehm et al. (2019) found that active deer mice (Peromyscus maniculatus) were more likely to consume a seed than to cache it; likewise, docile red-backed voles (Myodes gapperi) often cached seeds in optimal germination sites, while bold voles dispersed seeds farther afield than timid ones. Similarly, Boone et al. (2021) established that more docile mice consumed more preferred seeds and cached less preferred seeds, and increasing boldness affected the number of seeds potentially cached. As personality types vary in dispersal effectiveness at different stages, the composition of personality types can influence tree regeneration. Individuals who are fairly effective during all stages of dispersal (for example by dispersing seeds farther, caching them intact, and choosing cache sites that are optimal for germination) are likely better for plant dispersal than individuals who are effective dispersers at some stages, but negatively impact dispersal success in other stages (Zwolak and Sih 2020).

Furthermore, land use can influence the composition of personality types within a stand, suggesting that the way land is managed could negatively impact seed recruitment if certain practices favor specific personality types over others. For example, Brehm et al. (2019) reported that managing forest stands using even-aged silvicultural practices may negatively affect seed recruitment because even-aged stands favored mice with more active personality types that were more likely to consume than to cache seeds. This can be particularly important for plant species that are highly preferred by seed dispersers; some small mammals have the potential to harvest up to $95 \%$ of their favored tree seeds, resulting in a substantial reduction of seed recruitment (Lobo 2014). Considering personalities of seed dispersers may therefore provide useful insights for land managers.

\section{Regulation of pest species}

The regulation of pest species constitutes a key ecosystem service because these species (including both overabundant natives and invasive exotics) cause billions of dollars of damage worldwide each year (Pimentel et al. 2005) and pose major threats to human health. For example, more than 23,000 cases of human plague, an often-fatal infectious disease caused by the bacterium Yersinia pestis (which is spread by fleas that hitch a ride on one of the world most invasive species, the black rat [Rattus rattus]), were reported in the period 1998-2008 (Capizzi et al. 2014). While cartoon 
characters like Mickey Mouse, Ratbert, and Ratatouille testify to the acknowledgement of personality in rodents, scientists are lagging behind as the effects of animal personality on the regulation of pest species have yet to be tested directly. Nevertheless, we hypothesize that a relationship between personality and the provisioning of this ecosystem service is likely to be present (see also Garvey et al. 2020). We found three lines of empirical evidence in support of our hypothesis, which include effects both on pests and on their regulators (ie predators).

First, personality affects ecological parameters of pest species, such as individual survival (Brodin et al. 2019) and dispersal (Chapple et al. 2012; Michelangeli et al. 2017). Second, personality has been shown to affect the response of pests to control methods like insecticides (Morales et al. 2013) and trapping (Boon et al. 2008; but see Brehm and Mortelliti 2018). Trapping is one of the most common methods for controlling pests (such as rodents) (Capizzi et al. 2014) and indeed intraspecific variation in trappability has been found to reduce the effectiveness of pest control methods (Tuyttens et al. 1999). Third, personality can influence the effectiveness of predators, which are important contributors to biological control methods, or can constitute pests themselves (Moseby et al. 2015). For example, empirical studies have found that predator personalities can control the composition of prey communities (Start and Gilbert 2017), which implies a possible effect of personality on biocontrol methods. Conversely, there is also evidence that prey personality influences predation risk (Santos et al. 2015). More generally, research has shown that personality may affect foraging, such as food intake (Biro and Stamps 2008), which could potentially impact the effectiveness of biocontrol species. Finally, Royauté et al. (2015) found that exposure to pesticides influenced personality expression in the bronze jumping spider (Eris militaris), a native predator that controls pest species, which could in turn influence the effectiveness of pesticides. This example demonstrates the effect that artificial control methods (ie pesticides) may have on biocontrol agents (ie spiders) via mediation of personality.

In their recent paper building on signal detection theory, Garvey et al. (2020) proposed a framework to incorporate personality research into pest management. Identifying and exploiting individual variation in behaviors related to "feeding, fleeing, fighting, and fornication" - the four core motivators of animal behavior - may maximize the effectiveness of management strategies, and could prove particularly effective in managing rogue (causing disproportionate levels of damage) and recalcitrant (avoiding standard control measures) individuals. Indeed, predator profiling at the individual level has been suggested as a means of controlling invasive predators (Moseby et al.2015) and invasive species in general (Chapple et al.2012).

\section{Cetaceans and ecotourism}

Moby Dick, one of the world's most famous - albeit fictional - individual wild animals, is emblematic of a well-known phenomenon, the variability of cetacean behavior. An armada of whale-watching boats operating from the Azores to Zanzibar has introduced millions of people to individual whales and dolphins that are routinely more "friendly", "curious", or "playful" than others. Some cetaceans are recognizable individually and repeatedly approach boats for close encounters that are far more exciting than viewing from a legally mandated distance (CunninghamSmith et al. 2006). Consider "Fungie", a wild bottlenose dolphin (Tursiops truncatus) that attracted millions of tourists to Dingle, Ireland, from 1983 to 2021; he had his own Facebook and Twitter accounts. It is reasonable to surmise that much of the popularity of whale watching is based on interactive individuals, rather than those that keep their distance. Although precise quantification of the economic impact of these individuals is not possible, with annual direct revenues from global whale watching estimated at over US $\$ 2$ billion (Cisneros-Montemayor et al. 2010), even if only $10 \%$ of the industry were dependent on "friendly" individuals, this would be fiscally noteworthy. Unfortunately, quantification of cetacean personalities is quite limited, although multiple papers have qualitatively described personality traits of captive bottlenoses, especially with respect to sociality (eg Highfill and Kuczaj 2010). Individual variation in the behavioral interactions of wild bottlenoses with humans has been studied, but not in a framework that would allow identification of stable personalities (Powell and Wells 2011).

In summary, personalities have been documented in some cetacean species and by extrapolation it seems highly likely that these traits strongly influence their role in whale watching, an economically important cultural ecosystem service. More broadly, nature tourism is a vast enterprise reaching far beyond cetaceans and involving myriad species and ecosystems. Maintaining a safe distance is a recurring theme for viewing wild animals, but there are many cases, especially among primates and other mammals, in which the personality of individual animals has the potential to reach across the divide and affect a person's experience profoundly. That said, there is also the potential for negative consequences tied to animals becoming habituated to humans, for instance by increasing the likelihood of human-wildlife conflicts (Wilson et al.2020).

\section{Soil}

Is it farfetched to think that earthworms may have personalities that could shape one of the most critical resources on earth - its soil? Not at all. Charles Darwin devoted over 30 years to experiments on earthworms in his own garden, basing his final book on the topic and noting that some earthworms appeared "timid" whereas others were "brave", and that some were "neat and tidy" but others were "slovenly" (Darwin 1881). Within the soil's diverse fauna, earthworms have been widely recognized as key agents in maintaining the quality of agricultural 
soils (Briones and Schmidt 2017). In fact, one hectare of agricultural land can contain upward of 7 million earthworms, the activities of which can transfer 20-25 tons of topsoil to the surface each year (Sinha et al. 2010). In addition to Darwin's garden experiments, Nakashima et al. (2018) demonstrated that individual earthworms differ in their ability to learn and solve problems. These results suggest that individuals may vary in their ability to perform tasks effectively, such as creating burrows and burying organic material. As such, the daily activity patterns of earthworms, and whether they are "tidy" or "slovenly", likely impact soil characteristics.

If even lowly worms have personalities, what about the thousands of arthropod species that inhabit soils, shredding litter and breaking down material while consuming its surficial bacteria and fungi? Indeed, diverse studies have shown that arthropods exhibit numerous personality traits, including timidness/boldness, activity level, aggression, and even sociality (Kralj-Fišer and Schuett 2014). Modlmeier et al. (2015) discussed the potential for nest-building arthropods to impact tropical ecosystems and highlighted case studies where arthropod personalities can impact rates of consumption and diet breadth, and potentially mediate the composition of the arthropod community.

Larger burrowing species, including many small mammals and amphibians, also alter the physical and chemical properties of soil (Platt et al. 2016; Mallen-Cooper et al. 2019). Prairie dogs (Cynomys spp), a burrowing mammal known to alter soil structure and quality, have been termed "ecosystem engineers" due to the extensive burrow systems they construct (Platt et al. 2016) and their ability to transform entire grasslands. Several burrowing species have been shown to exhibit consistent individual differences in behaviors that impact activity patterns, space use, and feeding rates. Individual burrowers may affect soil structure and quality to different extents by occupying different spatial niches, dispersing over longer distances, or displaying greater overall activity (Gharnit et al.2020). For example, in the case of prairie dogs, individuals with different personality types may play slightly different roles in the family group (ie exhibiting social niche specialization) (Bergmüller and Taborsky 2010). Highly active individuals may spend more time maintaining and excavating the burrow system, whereas less active individuals may spend relatively more time monitoring for predators. The personality composition of a family group would therefore drive the effects of these ecosystem engineers on soil properties in a grassland ecosystem.

\section{Discussion}

\section{Busy as a bee or timid as a mouse?}

Humans routinely use animals in metaphors to describe human behavior, yet we rarely consider the real-world implications of personality in animals, as illustrated in the four examples presented above. These examples demonstrate that there is vast potential to explore ways in which the personality composition of a population may affect the ecosystem services that the population provides (Figure 1). In particular, it seems clear that using metrics averaged across populations may be misleading if some individuals have a disproportionate impact (ie acting as keystone individuals). For example, individuals that move seeds or pollen far beyond the population average are likely to play an outsized role in the dispersal of plants (Modlmeier et al. 2014), and predators that are more effective at removing invasive prey than average may play a disproportionate role in pest regulation. Similarly, population averages may provide an inadequate understanding of the provisioning of ecosystem services if different segments of the population, representing different personality types, perform quite differently - especially given that the prevalence of those types can change over time for a variety of reasons, including land-use change (Miranda et al. 2013; Brehm et al. 2019). Consequently, by modifying the proportion of different personality types in a population, we may also be possibly affecting the provision of ecosystem services.

We propose a four-step process for ecologists who wish to investigate the role of personalities in modulating ecosystem services and offer management advice based on their research (Figure 2).

\section{Step 1: foundational work}

This step starts with generating hypotheses and gathering evidence of measurable personality traits in a target species (eg is there repeatable variation in boldness in a species known to play an important ecological role? Dingemanse and Wright 2020). Foundational work should also include an assessment of alternative relevant traits that may affect ecosystem services (eg will boldness or aggressiveness have a greater effect on the modulation of services?) and developing accurate methods to measure these traits in the field or lab.

\section{Step 2: assessment}

Assessment should be focused on carefully quantifying the relationship between personality and the behavior that produces a service. For example, Brehm et al. (2019) found that four personality traits affected the ecosystem service of seed dispersal by detecting significant relationships between these personality traits and seed choice, dispersal distance, seed fate, and cache location. Similarly, Burns (2005) noted that fast, "impulsive" bees likely forage on flowers of simple design whereas slower, "reflective" bees likely forage on complex flowers.

\section{Step 3: validation}

Validation requires confirmation of the relevance of personality by estimating the extent to which the actual personality composition of a population affects the provision of a service. This is a necessary step because even in the presence of a 


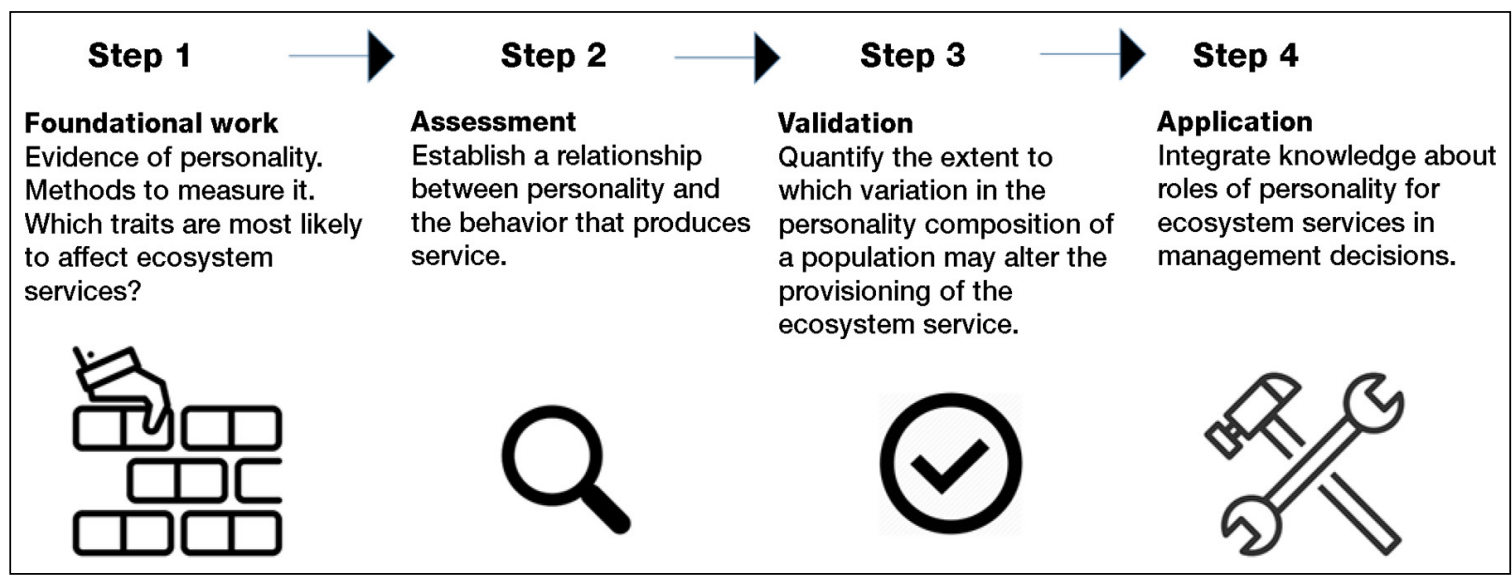

Figure 2. Four-step road map for ecologists planning to investigate the role of personalities in modulating ecosystem services and develop management strategies based on their results.

strong relationship between personality and an ecosystem service, the presence of individuals with varying personality types may possibly compensate for one another. In other words, in some cases population averages may tell the story sufficiently (at least in one place and one time).

\section{Step 4: application}

This is the final stage, in which scientists use their knowledge about the roles of personality to inform management decisions. Managing for animal personality is not a futuristic fantasy; humans have indeed been doing it for millennia, primarily through the process of domestication, which involves selecting for certain behavioral types (such as aggressive or docile dogs, rabbits, horses, or cats). Likewise, we routinely remove aggressive individuals from wild populations wherever people concentrate (eg dangerous bears [Ursus spp] in parks) and inevitably the most curious individuals are removed when bait is used for hunting. Conservation biologists have long argued that large, diverse populations should be a priority for conservation, but behavioral variation has rarely been explicitly considered. Indeed, given the genetic basis of personality (Dochtermann et al. 2015; Bengston et al. 2018), it is possible that when supporting the genetic richness of populations we are also indirectly maintaining a diversity of personalities, but only through future work will we confirm for which species and populations this is true. The direct and indirect empirical evidence we have compiled here strongly suggest that the time is ripe to begin accounting for behavioral variation among individuals in the management of ecosystem services.

\section{Acknowledgements}

$\mathrm{K}$ Currier produced the images in Figure 1. This project was supported by the USDA National Institute of Food and Agriculture, McIntire-Stennis Project numbers ME041913 and ME021705 through the Maine Agricultural \& Forest Experiment Station (MAFES). AM was partially supported by a US National Science Foundation Career Award
(IOS\#1940525) during preparation of this manuscript. MAFES Publication Number 3855.

\section{References}

Bengston SE, Dahan RA, Donaldson Z, et al. 2018. Genomic tools for behavioural ecologists to understand repeatable individual differences in behaviour. Nature Ecol Evol 2: 944-55.

Bergmüller R and Taborsky M. 2010. Animal personality due to social niche specialisation. Trends Ecol Evol 25: 504-11.

Biro PA and Stamps JA. 2008. Are animal personality traits linked to life-history productivity? Trends Ecol Evol 23: 361-68.

Boon AK, Réale D, and Boutin S. 2008. Personality, habitat use, and their consequences for survival in North American red squirrels Tamiasciurus hudsonicus. Oikos 117: 1321-28.

Boone SR, Brehm AM, and Mortelliti A. 2021. Seed predation and dispersal by small mammals in a landscape of fear: effects of personality, predation risk and land-use change. Oikos; https://doi. org/10.1111/oik.08232.

Brehm AM and Mortelliti A. 2018. Mind the trap: large-scale field experiment shows that trappability is not a proxy for personality. Anim Behav 142: 101-12.

Brehm AM, Mortelliti A, Maynard GA, and Zydlewski J. 2019. Landuse change and the ecological consequences of personality in small mammals. Ecol Lett 22: 1387-95.

Briones MJI and Schmidt O. 2017. Conventional tillage decreases the abundance and biomass of earthworms and alters their community structure in a global meta-analysis. Glob Change Biol 23: 4396-419.

Brodin T, Cote J, Sih A, and Fogarty S. 2019. Personality-dependent survival of the invasive mosquitofish: being social can be deadly. Aquat Invasions 14: 465-77.

Burns JG. 2005. Impulsive bees forage better: the advantage of quick, sometimes inaccurate foraging decisions. Anim Behav 70: e1-5.

Capizzi D, Bertolino S, and Mortelliti A. 2014. Rating the rat: global patterns and research priorities in impacts and management of rodent pests. Mammal Rev 44: 148-62.

Chapple DG, Simmonds SM, and Wong BBM. 2012. Can behavioral and personality traits influence the success of unintentional species introductions? Trends Ecol Evol 27: 57-64. 
Cisneros-Montemayor AM, Sumaila UR, Kaschner K, and Pauly D. 2010. The global potential for whale watching. Mar Policy 34: 1273-78.

Cunningham-Smith P, Colbert DE, Wells RS, and Speakman T. 2006. Evaluation of human interactions with a provisioned wild bottlenose dolphin (Tursiops truncatus) near Sarasota Bay, Florida, and efforts to curtail the interactions. Aquat Mamm 32: 346-56.

Darwin CR. 1881. The formation of vegetable mould, through the action of worms. London, UK: John Murray.

Dingemanse NJ and Wright J. 2020. Criteria for acceptable studies of animal personality and behavioural syndromes. Ethology 126: 865-69.

Dochtermann NA, Schwab T, and Sih A. 2015. The contribution of additive genetic variation to personality variation: heritability of personality. P Roy Soc B-Biol Sci 282: 20142201.

Garvey PM, Banks PB, Suraci JP, et al. 2020. Leveraging motivations, personality, and sensory cues for vertebrate pest management. Trends Ecol Evol 35: 990-1000.

Gharnit E, Bergeron P, Garant D, and Réale D. 2020. Exploration profiles drive activity patterns and temporal niche specialization in a wild rodent. Behav Ecol 31: 772-83.

Highfill LE and Kuczaj SA. 2010. How studies of wild and captive dolphins contribute to our understanding of individual differences and personality. Int J Comp Psychol 23: 269-77.

Kralj-Fišer S and Schuett W. 2014. Studying personality variation in invertebrates: why bother? Anim Behav 91: 41-52.

Lobo N. 2014. Conifer seed predation by terrestrial small mammals: a review of the patterns, implications, and limitations of top-down and bottom-up interactions. Forest Ecol Manag 328: 45-54.

Mallen-Cooper M, Nakagawa S, and Eldridge DJ. 2019. Global metaanalysis of soil-disturbing vertebrates reveals strong effects on ecosystem patterns and processes. Global Ecol Biogeogr 28: 661-79.

Michelangeli M, Smith CR, Wong BBM, and Chapple DG. 2017. Aggression mediates dispersal tendency in an invasive lizard. Anim Behav 133: 29-34.

Miranda AC, Schielzeth H, Sonntag T, and Partecke J. 2013. Urbanization and its effects on personality traits: a result of microevolution or phenotypic plasticity? Glob Change Biol 19: 2634-44.

Modlmeier AP, Keiser CN, Watters JV, et al. 2014. The keystone individual concept: an ecological and evolutionary overview. Anim Behav 89: 53-62.

Modlmeier AP, Keiser CN, Wright CM, et al. 2015. Integrating animal personality into insect population and community ecology. Curr Opin Insect Sci 9: 77-85.

Morales JA, Cardoso DG, Della Lucia TMC, and Guedes RNC. 2013. Weevil $\times$ insecticide: does "personality" matter? PLOS ONE 8: 34-37.

Moseby KE, Peacock DE, and Read JL. 2015. Catastrophic cat predation: a call for predator profiling in wildlife protection programs. Biol Conserv 191: 331-40.

Muir J. 1911. My first summer in the Sierra. Boston, MA: Houghton Mifflin.
Nakashima T, Mushiake H, and Sakamoto K. 2018. Earthworm individualities when facing a conflict between turn alternation and aversive learning. Biophys Physicobiol 15: 159-64.

Ollerton J, Winfree R, and Tarrant S. 2011. How many flowering plants are pollinated by animals? Oikos 120: 321-26.

Pimentel D, Zuniga R, and Morrison D. 2005. Update on the environmental and economic costs associated with alien-invasive species in the United States. Ecol Econ 52: 273-88.

Platt BF, Kolb DJ, Kunhardt CG, et al. 2016. Burrowing through the literature: the impact of soil-disturbing vertebrates on physical and chemical properties of soil. Soil Sci 181: 175-91.

Powell JR and Wells RS. 2011. Recreational fishing depredation and associated behaviors involving common bottlenose dolphins (Tursiops truncatus) in Sarasota Bay, Florida. Mar Mammal Sci 27: 111-29.

Réale D, Dingemanse NJ, Kazem AJN, and Wright J. 2010. Evolutionary and ecological approaches to the study of personality. Philos T Roy Soc B 365: 3937-46.

Royauté R, Buddle CM, and Vincent C. 2015. Under the influence: sublethal exposure to an insecticide affects personality expression in a jumping spider. Funct Ecol 29: 962-70.

Santos CD, Cramer JF, Pâraû LG, et al. 2015. Personality and morphological traits affect pigeon survival from raptor attacks. Sci Rep-UK 5: 1-8.

Sinha RK, Agarwal S, Chauhan K, et al. 2010. Vermiculture technology: reviving the dreams of Sir Charles Darwin for scientific use of earthworms in sustainable development programs. Technol Investment 1: 155-72.

Start D and Gilbert B. 2017. Predator personality structures prey communities and trophic cascades. Ecol Lett 20: 366-74.

Thom D and Seidl R. 2016. Natural disturbance impacts on ecosystem services and biodiversity in temperate and boreal forests. Biol Rev 91: 760-81.

Tuyttens FAM, Macdonald DW, Delahay R, et al. 1999. Differences in trappability of European badgers Meles meles in three populations in England. J Appl Ecol 36: 1051-62.

Walton A and Toth AL. 2016. Variation in individual worker honey bee behavior shows hallmarks of personality. Behav Ecol Sociobiol 70: 999-1010.

Watts I. 1777. Against idleness and mischief. Song XX. In: Divine songs: attempted in easy language for the use of children. London: privately printed (for Buckland J, Rivington JF, Rivington C, et al.). https://bit.ly/3928CjP.

Wilson MW, Ridlon AD, Gaynor KM, et al.2020. Ecological impacts of human-induced animal behaviour change. Ecol Lett 23: 1522-36.

Wolf $\mathrm{M}$ and Weissing FJ. 2012. Animal personalities: consequences for ecology and evolution. Trends Ecol Evol 27: 452-61.

Wray MK, Mattila HR, and Seeley TD. 2011. Collective personalities in honeybee colonies are linked to colony fitness. Anim Behav 81: 559-68.

Zwolak R and Sih A. 2020. Animal personalities and seed dispersal: a conceptual review. Funct Ecol 34: 1294-310. 